\title{
Thromboelastometric Profile in Patients with Prothrombotic Risk Factors Undergoing Liver Transplantation
}

José Carlos Rodrigues Nascimento ${ }^{1-3^{*}}$, Rodrigo Dornfeld Escalante ${ }^{1}$, David Silveira Marinho², Cláudia Regina Fernandes ${ }^{3}$, Tayná Lima Freire ${ }^{2}$ and Aline Menezes Sampaio ${ }^{2}$

${ }^{1}$ Department of Postgraduate of Medical Sciences, University of Fortaleza, Fortaleza-CE, Brazil

${ }^{2}$ Department of Anesthesia and Liver Transplantation, General Hospital of Fortaleza, Fortaleza-CE, Brazil

${ }^{3}$ Department of Clinical Medicine, School of Medicine, Federal University of Ceara, Fortaleza-CE, Brazil

"Corresponding author: José Carlos Rodrigues Nascimento, Department of Postgraduate of Medical Sciences' University of Fortaleza, Street Antonele Bezerra, 280, AP 202, Meireles, Fortaleza-CE, Brazil, Tel: 5585 99668-8500; E-mail: jcr.nascimento@hotmail.com

Received date: June 12, 2017; Accepted date: July 14, 2017; Published date: July 21, 2017

Copyright: (c) 2017 Nascimento JCR, et al. This is an open-access article distributed under the terms of the Creative Commons Attribution License, which permits unrestricted use, distribution and reproduction in any medium, provided the original author and source are credited.

\section{Abstract}

Background: Orthotopic liver transplantation (OLT) is a highly complex procedure and can offer difficult intraoperative control in patients with coagulopathy. The present study aimed to evaluate the profile of coagulation by Rotation thromboelastometry $\left(\right.$ ROTEM $\left.^{\circledR}\right)$ in the intraoperative of patients with prothrombotic risk factors submitted to liver transplantation.

Methods: A prospective, observational pilot study, in which 24 patients submitted to OLT, of both sexes and age from 18 years, were included in the period from October 2014 to June 2017. Three samples were taken intraoperatively to analyze the profile of coagulation through the thromboelastometry assays (EXTEM, FIBTEM, INTEM and HEPTEM).

Results: In the analysis of the tests in the EXTEM (clotting time [CT] and maximum clot firmness [MCF]) and INTEM (MCF), there was hypocoagulation along the OLT, with no statistical difference between the values obtained. In the FIBTEM tests (amplitude in 10 minutes [A10] and MCF), There was reduction in the neohepatic phase (stage III) in relation to the beginning of surgery (stage I), with statistical significance $(P=0.0424$ and 0.0227 , respectively). In the analysis of CT in the INTEM, there was an increase in the stage III in relation to stage I and anhepatic phase (stage II), with statistical significance $(P=0.0004$ and 0.0012 , respectively). The fibrinolytic activity by maximum lysis (ML) was higher in the stage I and stage II in relation to stage III, when analyzed by the EXTEM, presenting statistical significance $(P=0.0016$ and 0.0035 , respectively).

Conclusion: In patients with prothrombotic risk factors, data from the ROTEM ${ }^{\circledR}$ analysis showed some statistically significant changes, but we cannot say that it showed tendency to hypocoagulation, when there was not significance in most other tests. Therefore, in the FIBTEM tests the consumption of fibrinogen was more accentuated in stage III in relation to stage I and in relation to stage III, when analyzed by INTEM CT and EXTEM $\mathrm{ML}$, the presence of heparin was higher and fibrinolysis was less pronounced, respectively.

Keywords: Liver transplantation; Coagulation disorders; Thromboelastometry; Prothrombotic.

\section{Abbreviations:}

OLT: Orthotopic Liver Transplantation; ROTEM: Rotation Thromboelastometry; CT: Clotting Time; ML: Maximum Lysis; Hb: Hemoglobin; MCF: Maximum Clot Firmness; A10: Amplitude in 10 minutes; ANOVA: Analysis of Variance; MELD: Model for End-Stage Liver Disease; PAI-1: Plasminogen Activator Inhibitor type-1; t-PA: Tissue Plasminogen Activator; u-PA: Urokinase-type Plasminogen Activator.

\section{Introduction}

Orthotopic liver transplantation (OLT) is the treatment of choice for patients with late stage decompensated liver disease [1]. Intraoperatively, control of coagulation disturbances may be challenging, especially in patients presenting with coagulopathy and portal hypertension [2].

Historically, OLT has been associated with transfusion of large amounts of blood derivatives [3-7]. Currently, there is a progressive reduction of perioperative blood loss due to advances in surgical skills, anesthetic management and coagulation monitoring in general [8-12].

Although the cause of hemorrhage is multifactorial, complex and profound coagulation changes are common during liver transplantation. A such, baseline coagulation status and additional intraoperative disorders (e.g. hemodilution, consumption of factors and hyperfibrinolysis) contribute to intraoperative blood loss [13-18].

It is important to note that cirrhotic patients have a decrease in procoagulant factors (leading to bleeding) and anticoagulant factors (leading to thrombosis). They may also present with thrombocytopenia, hyperfibrinolysis and von Willebrand factor abnormalities $[19,20]$. 
Page 2 of 6

Nevertheless, some poorly studied patients may present with prothrombotic risk factors and high hemostatic capacity due to modified local flow dynamics and several acquired and genetic factors. This population presumably include patients with Budd-Chiari syndrome, protein $\mathrm{C}$ deficiency, malignant disease, multiple organ transplants and chronic renal failure, as well as retransplantation for portal vein or hepatic artery thrombosis, pre-existing thrombotic diseases and non-alcoholic steatohepatitis (NASH) [13,20-27].

Other risks for hypercoagulability also include primary biliary cirrhosis and primary sclerosing cholangitis, as well as high levels of coagulation factors (thrombin-antithrombin complex) and plasminogen activator inhibitor type 1 (PAI-1) are higher [21-26]. Although several studies have shown coagulation changes during the intraoperative period of patients undergoing liver transplantation, there are few studies specifically evaluated patients with prothrombotic risk factors. In this study, we evaluated the thromboelastometric profile of this group of patients.

\section{Methods}

This prospective observational pilot study was approved by the Institutional Review Board of the General Hospital of Fortaleza, Brazil (\#794061). Written informed consent was obtained from the enrolled patients or their next of kin.
We studied adult patients ( $\geq 18$ years old) who received an orthotopic liver transplantation from October 2014 to June 2017 and had a presumedly prothrombotic coagulations status according to some authors [13,20-27], such as: Budd-Chiari syndrome, protein C deficiency, malignant disease, multiple organ transplants, chronic renal failure, retransplantation for portal vein and hepatic artery thrombosis, portal vein and hepatic artery thrombosis, primary biliary cirrhosis.

All patients were submitted to liver transplantation by the piggyback surgical technique $[4,12]$. During the surgery preconditions of hemostasis were maintained within adequate ranges: $\mathrm{pH} \geq 7.3$, Temperature $\geq 36^{\circ} \mathrm{C}$, ionic calcium $\geq 1.1 \mathrm{mmol} / \mathrm{L}^{-1}$ and hemoglobin $(\mathrm{Hb}) \geq 8 \mathrm{~g} / \mathrm{dL}^{-1}$.

Blood samples were collected hourly for blood gas analysis and at three times for rotational thromboelastometry (ROTEM', Pentapharm, Germany): at the beginning of surgery (stage I) per before the portal vein anastomosis on anhepatic phase (stage II) and before the anastomosis of the bile ducts in the neohepatic phase (stage III).

Thromboelastometric variables from the assays EXTEM, INTEM, FIBTEM, APTEM and HEPTEM were recorded. Signs of hypocoagulation and presence of microvascular bleeding were inspected for and, upon its detection per a protocol for hemostatic support was initiated (table 1). Obtained thromboelastometric variables were compared to normal values $[28,29]$.

\begin{tabular}{|c|c|c|}
\hline ROTEM $^{\circledR}$ & Coagulopathy & Treatment Options \\
\hline EXTEM CT $>80-100 \mathrm{~s}$ & $\downarrow$ plasma factors & $\begin{array}{l}\text { PCC: } 25-40 \mathrm{IU} / \mathrm{kg}^{-1} \text { and } / \mathrm{or} \\
\text { FFP: } 15-20 \mathrm{~m} / \mathrm{kg}^{-1}\end{array}$ \\
\hline $\begin{array}{l}\text { EXTEM A } 10<30 \mathrm{~mm} \text { ou } M C F<35 \mathrm{~mm} \text {, FIBTEM } \\
\text { MCF }>9 \mathrm{~mm}\end{array}$ & $\downarrow$ platelets & $\begin{array}{l}\text { Platelets: } 1 \mathrm{U} \text { for each } 7 \text { to } 10 \mathrm{~kg} \text { or } 1 \text { apheresis or } 1 \\
\text { buffy coat }\end{array}$ \\
\hline $\begin{array}{l}\text { EXTEM A } 10<30 \mathrm{~mm} \text { ou } M C F<35 \mathrm{~mm} \text {, FIBTEM } \\
M C F<9 \mathrm{~mm}\end{array}$ & $\downarrow$ fibrinogen & $\begin{array}{l}\text { Fibrinogen }(\mathrm{g})=\mathrm{MCF} \text { in } \triangle \text { FIBTEM }(\mathrm{mm}) \times \text { weight } \\
(\mathrm{kg}) / 140\end{array}$ \\
\hline INTEM CT>240S e CT $\mathrm{HEPTEM}_{\text {H }} / \mathrm{CT}_{\text {INTEM }}<0.8$ & $\uparrow$ heparin & Protamine: $50-100 \mathrm{mg}$ \\
\hline INTEM CT>240S e CT HEPTEM $/ \mathrm{CT}_{\text {INTEM }} \geq 0.8$ & $\downarrow$ plasma factors & FFP: $15-20 \mathrm{ml} / \mathrm{kg}^{-1}$ \\
\hline EXTEM ML $>15 \%$ e APTEM $M L<15 \%$ & $\uparrow$ fibrinolysis & EACA: $50 \mathrm{mg} / \mathrm{kg}^{-1}$ \\
\hline
\end{tabular}

Table 1: Algorithm for treatment of coagulation disorders and fibrinolysis according to ROTEM.

For normality, the D'Agostino \& Pearson and Shapiro-Wilk tests were performed. In the parametric tests, analysis of variance (ANOVA) was used and the significance was studied by the Tukey's test for multiple comparisons with a 95\% confidence interval. In nonparametric tests, Friedman and Kruskal-Wallis tests were used in association with the Dunn's test for multiple comparisons.

\section{Results}

In the study period, 24 patients were identified with a presumedly prothrombotic coagulations status, and their demographic and surgical data are summarized in table 2.

Coagulation parameters from EXTEM (Clotting time [CT] and maximum clot firmness $[\mathrm{MCF}]$ ) and INTEM (MCF), Showed a tendency of progressive hypocoagulation along the OLT, Although not statistically significant $(\mathrm{p}>0.05)$, as described in table 3 . In the
FIBTEM tests (amplitude in 10 minutes [A10] and MCF), showed a reduction in stage III in relation to stage I, with statistical significance $(\mathrm{P}<0.05)$, as described in table 3 .

Stage III clotting time of INTEM showed a statistically significant elongation in comparison with stages I and II $(\mathrm{P}<0.05)$, as illustrated in figure 1. Further, $\mathrm{CT}_{\text {HEPTEM }} / \mathrm{CT}_{\text {INTEM }}$ ratio of stage III was reduced when compared with previous samples, without statistical significance, as described in table 3. Clotting time elongation at INTEM was detected in 17 patients $(70.8 \%)$; between these patients, protamine was administered to $5(29.4 \%)$ in stage III, $2(11.8 \%)$ in stage II and $2(11.8 \%)$ in both stages I and III.

\begin{tabular}{|l|l|}
\hline Variable & Patients $(\mathbf{n}=\mathbf{2 4})$ \\
\hline Age & $51.8( \pm 9.4)$ years* \\
\hline Weight & $67.4( \pm 13.9) \mathrm{kg}^{*}$ \\
\hline
\end{tabular}


Citation: Nascimento JCR, Escalante RD, Marinho DS, Fernandes CR, Freire TL, et al. (2017) Thromboelastometric Profile in Patients with Prothrombotic Risk Factors Undergoing Liver Transplantation. J Transplant Technol Res 7: 175. doi:10.4172/2161-0991.1000175

Page 3 of 6

\begin{tabular}{|c|c|}
\hline \multicolumn{2}{|l|}{ Gender } \\
\hline Male & $13(54.0 \%)$ \\
\hline Female & $11(46.0 \%)$ \\
\hline Score MELD & $24.0( \pm 6.9)^{*}$ \\
\hline \multicolumn{2}{|l|}{ Causes } \\
\hline Hepatocellular carcinoma & $11(46.0 \%)$ \\
\hline PSC and PBC & $05(21.0 \%)$ \\
\hline $\begin{array}{l}\text { Retransplantation for hepatic artery } \\
\text { thrombosis }\end{array}$ & $04(17.0 \%)$ \\
\hline Portal thrombosis & $02(8.0 \%)$ \\
\hline CRF and $C$ virus & $02(8.0 \%)$ \\
\hline \multicolumn{2}{|l|}{ ABO Group } \\
\hline 0 & $12(50.0 \%)$ \\
\hline
\end{tabular}

\begin{tabular}{|l|l|}
\hline$A$ & $09(37.5 \%)$ \\
\hline$B$ & $02(8.3 \%)$ \\
\hline$A B$ & $01(4.2 \%)$ \\
\hline Duration of surgery & $341.7( \pm 81.9) \mathrm{min}^{*}$ \\
\hline
\end{tabular}

*Mean \pm SD (Standard Deviation), MELD: Model for End-Stage Liver Disease; PSC and PBC: Primary Sclerosing Cholangitis (PSC) and Primary Biliary Cirrhosis (PBC); CRF: Chronic Renal Failure

Table 2: Demographic and surgical characteristics of the patients studied.

Fibrinolytic activity, as evaluated with maximum lysis of EXTEM, was significantly higher $(\mathrm{P}<0.05)$ in stages I and II in comparison with stage III, as depicted in figure 2. Treatment with epsilon aminocaproic acid (EACA) was administered in 3 patients $(12.5 \%)$, being one in stage I and two in stage II (table 3).

\begin{tabular}{|l|l|l|l|l|l|}
\hline Tests & Normal range & Stage I & Stage II & Stage III & P Value \\
\hline EXTEM & CT $(38-79 \mathrm{~s})$ & $76.25 \pm 25.13$ & $78.88 \pm 24.52$ & $103.3 \pm 85.9$ & NS \\
& MCF $(50-72 \mathrm{~mm})$ & $53.21 \pm 12.7$ & $49.75 \pm 12.95$ & $50.46 \pm 12.59$ & NS \\
\hline FIBTEM & A10 $(7-23 \mathrm{~mm})$ & $14.8 \pm 9.682$ & $10.71 \pm 7.715$ & $9.625 \pm 4.862$ & $0.0424^{*}$ \\
& MCF $(9-25 \mathrm{~mm})$ & $16.53 \pm 10.69$ & $12.37 \pm 9.209$ & $11.21 \pm 5.213$ & $0.0227^{*}$ \\
\hline INTEM & MCF $(50-72 \mathrm{~mm})$ & $51.96 \pm 12.97$ & $49.04 \pm 15.09$ & $48.63 \pm 9.65$ & NS \\
\hline $\begin{array}{l}\text { CT } \\
\text { CT } \text { IITTEM }_{\text {INTEM }}\end{array}$ & $>0.8$ & $0.85 \pm 0.08$ & $0.76 \pm 0.20$ & $0.75 \pm 0.19$ & NS \\
\hline
\end{tabular}

Data are shown as Mean \pm Standard Deviation. ANOVA test, Friedman test and Kruskal-Wallis test were used to compare groups. Stage I = beginning of surgery; stage II = anhepatic phase; stage III = neohepatic phase; CT = clotting time; MCF = maximum clot firmness; $\mathrm{A} 10=$ amplitude 10 min after CT; NS: not significant; (*stage I vs. stage III); ${ }^{*} \mathrm{P}<0.05$.

Table 3: Analysis of the tests of the EXTEM, FIBTEM, INTEM and HEPTEM in the stages of the OLT.

\section{Discussion}

This study aimed to evaluate the thromboelastometric profile of patients traditionally presumed to have a large hemostatic reserve, less fibrinolysis, low risk of blood loss and a greater predisposition to hypercoagulation or high risk of thromboembolic complications $[24,27,30]$.

Krzanicki et al. [31] observed in a retrospective study with 124 patients undergoing OLT and monitoring with $\mathrm{TEG}^{\oplus}$, a high rate of hypercoagulability in patients with primary biliary cirrhosis $(85.7 \%)$ and in those with primary sclerosing cholangitis and fulminant hepatic insufficiency (50\%).

Ritter et al. [26] evidenced in a retrospective study that hemostatic parameters such as platelet counts, coagulation factors (II, V, VII, IX and $\mathrm{X}$ ) and antithrombin III presented less changes in patients with primary biliary cirrhosis and primary sclerosing cholangitis, when compared with chronic hepatitis.

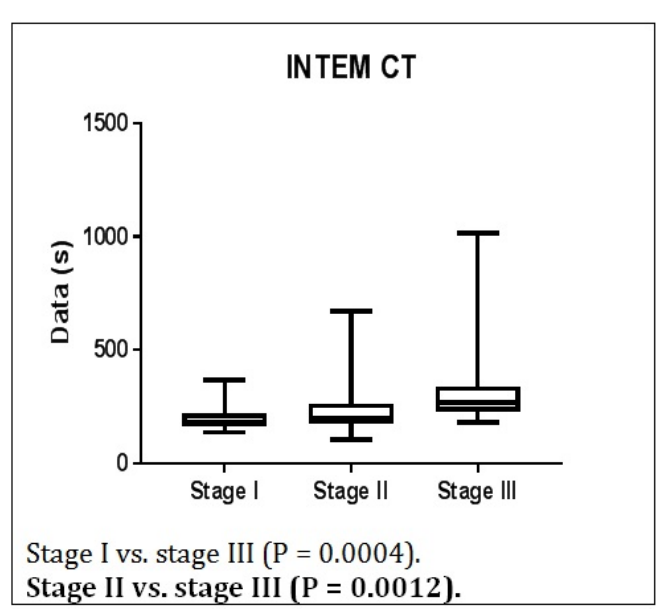

Figure 1: Analysis of the ITEM CT parameters in the OLT stages.

Friedman test; stage I=beginning of surgery; stage $\mathrm{II}=$ anhepatic phase; stage III=neohepatic phase; $\mathrm{CT}=$ clotting time; $\mathrm{P}<0.05$. 


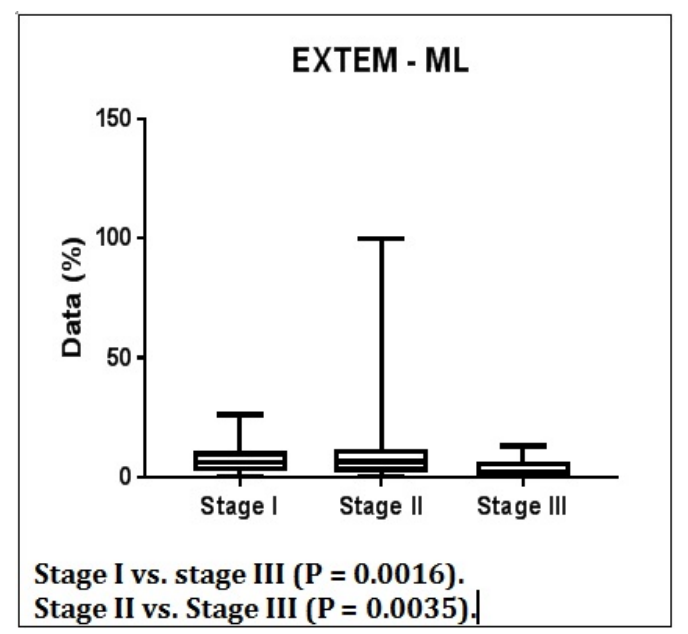

Figure 2: Analysis of the ML in the OLT stage by EXTEM.

Friedman test; stage I=beginning of surgery; stage $\mathrm{II}=$ anhepatic phase; stage III=neohepatic phase; $\mathrm{ML}=$ maximum lysis; $\mathrm{P}<0.05$.

The OLT has been historically connected with hemostatic reserve depletion, large bleeds and demand for hemostasis support measures. However, in patients whose hemostatic reserve has not been depleted, the use of certain blood products (factor concentrates) or synthetic compounds (such as desmopressin, antifibrinolytics and recombinant factor VIIa) may be associated with thrombotic complications $[20,22,25,30]$.

The historical difficulty in identifying patients with prothrombotic states has been to find an accurate method of assessing the hemostatic reserve. Currently, global coagulation methods are progressively more widely available and are believed to reflect the state of coagulation more broadly and accurately. However, the definition of which test would be the gold standard for assessing coagulation status (or hemostatic reserve) follows elusive [20,30].

Another difficulty is that many liver transplant centers do not have these exams. In these cases, due to the inability to evaluate hemostasis in real time, the anesthesiologist is forced to orient their conduits based on predefined labels on hemostasis in certain etiologies of cirrhosis. In this sense, in a patient predicted to be "prothrombotic", it is possible that a given pro-hemostatic therapy is summarily contraindicated or postponed due to fears of thromboembolic events. The use of antifibrinolytics, for example, is usually contraindicated or used with restrictions in patients with a prothrombotic tendency $[20,30]$.

In this series, cryoprecipitate, fresh frozen plasma, platelets, prothrombin complex concentrate, antifibrinolytic, fibrinogen concentrate and protamine were administered, when considered necessary as suggested by the intraoperative findings in ROTEM', according to the algorithm of Table 1 .

However, in spite of corrections with blood products, there was hypocoagulation in the thromboelastogram throughout the liver transplantation, corroborating with the blood loss, hemodilution and the consumption of coagulation factors that occur along the OLT $[6,7,20]$.
The deterioration of the fibrinogen concentration throughout the surgery was the most significant result among the blood components of this study, similar to the study by Hiippala et al. [32] where they showed that in acute bleeding, fibrinogen was the first coagulation factor to reach critical levels.

Also, severe coagulopathies may occur during OLT, mainly after reperfusion of the hepatic graft, having the release of heparin as a contributing factor [33].

Kettner et al. [34] demonstrated in one study that heparin-modified thromboelastography can identify the significant effects of heparin in the absence of exogenous heparin administration in patients undergoing OLT.

In this study, CT enlargement in the INTEM after reperfusion was represented in more than $53 \%$ of the patients due to the effect of heparin, in agreement with the study of Agarwal et al. [35] where they demonstrated in a retrospective and observational study of 211 patients undergoing liver transplantation that the prevalence of heparin was demonstrated in more than $80 \%$ of cases after reperfusion of the graft.

It is also important to mention that the fibrinolytic activity by ML in the EXTEM was less pronounced in stage III, measured after one hour of reperfusion, according to most studies, where the correction of hyperfibrinolysis usually occurs within one hour after reperfusion by the presence of hepatic clearance. As it is already well documented that the frequency of disorders associated with diseased organs such as platelet defects, decreased PAI-1, reduced synthesis and release of coagulation factors can lead to compromised hemostasis and hyperfibrinolysis, mainly during the anhepatic phase and immediately after organ reperfusion. The explanation for these findings may be due to the presence of increased levels of tissue plasminogen activator ( $t$ $\mathrm{PA}$ ) and urokinase-type plasminogen activator (u-PA) in the preanesthetic and anhepatic phases, as well as a pronounced release of $t$ PA of the endothelium of the graft soon after reperfusion and in the presence of the still non performing hepatic graft [36-38].

Himmelreich et al. [38] identified a slight increase in u-PA and t-PA levels during the preoperative period and a slight decrease in the preanesthetic and anhepatic phases. On the other hand, Dzik et al. [39] showed that there was a mild to moderate increase in u-PA antigen levels in some patients at the beginning of surgery, but the acute pathophysiological actions of systemic fibrinolytic activity are more influenced by t-PA in the anhepatic phase.

In this series the prominent fibrinolytic activity in the stage I and stage II and low in stage III by EXTEM, contradicted the study by Poon et al. [37] where fibrinolytic activity was low in beginning of surgery and anhepatic phase, rising soon after reperfusion in less than 30 minutes. As the samples were collected around 60 minutes after reperfusion, it is possible that the acute alterations of t-PA have already been dissipated [40-41], being able to explain the difference between the studies.

In this study, $12.5 \%$ of patients with hyperfibrinolysis, EACA treatment were effective in agreement as described by some authors in patients with cirrhosis or during liver transplantation [42-43].

ROTEM $^{\circ}$ was able to guide the transfusion when there was a real need. Roullet et al. [44] concluded that ROTEM ${ }^{\circ}$ is useful for the global evaluation of coagulation and the EXTEM was the most informative to evaluate the entire coagulation process. Therefore, the empirical use of 
Page 5 of 6

blood products uncontrolled by ROTEM ${ }^{\circ}$ should not be considered in the current real evidence in the literature [45].

The thromboelastic profile demonstrated in our results suggests that patients historically presumed to be prothrombotic may actually have coagulation within the range of values considered normal $[24,27,30]$. This finding reinforces the need for increased use of global coagulation tests so that potentially life-saving therapies are not contraindicated or postponed based solely on ill-defined and imprecise labels.

The present study has as limitations the observational nature of the research, small sample and no measurement of intraoperative bleeding. It is important to carry out prospective and randomized studies to be conducted in the future with a larger sample and prothrombotic risk factors derived from an actual hypercoagulability system, such as laboratory tests (anti-phospholipid antibodies, factor V Leiden SNP or protein $\mathrm{C}$ and $\mathrm{S}$ abnormalities), analyzing whether the administration of small doses of antifibrinolytics would reduce fibrinolysis and consequently bleeding in the perioperative period.

\section{Conclusion}

In conclusion, although the patients in this series may be prothrombotic, our results showed some statistically significant changes, but we cannot say that it showed a tendency to hypocoagulation, when there was no significance in most other ROTEM $^{\circ}$ tests. The diagnosis of the presence of heparin and/or heparinoids was superior in the neohepatic phase, being corrected effectively with the use of protamine, guided by thromboelastotometry and moreover, in this research fibrinolysis was more pronounced at the beginning of the transplantation and in the anhepatic phase.

\section{References}

1. Starzl TE, Demetris AJ, Van Thiel D (1989) Liver transplantation. N Engl J Med 321: 1014-1022.

2. Welch CS (1955) A note on transplantation of the whole liver in dogs. Transplant Bull 2: 54.

3. Feltracco P, Brezzi M, Barbieri S, Galligioni H, Milevoj M, et al. (2013) Blood loss, predictors of bleeding, transfusion practice and strategies of blood cell salvaging during liver transplantation. World J Hepatol 5: 1-15.

4. Hall TH, Dhir A (2013) Anesthesia for liver transplantation. Semin Cardiothorac Vasc Anesth 17: 180-94.

5. Hannaman MJ, Hevesi ZG (2011) Anesthesia care for liver transplantation. Transplant Rev (Orlando) 25: 36-43.

6. Pandey CK, Singh A, Kajal K, Dhankhar M, Tandon M, et al. (2015) Intraoperative blood loss in orthotopic liver transplantation: The predictive factors. World J Gastrointest Surg 7: 86-93.

7. Thomas D, Wee M, Clyburn P, Walker I, Brohi K, et al. (2010) Blood transfusion and the anaesthetist: Management of massive haemorrhage. Anaesthesia 65: 1153-1161.

8. Donohue CI, Mallett SV (2015) Reducing transfusion requirements in liver transplantation. World J Transplant 5: 165-182.

9. Görlinger K, Saner FH (2015) Prophylactic plasma and platelet transfusion in the critically Ill patient: Just useless and expensive or even harmful? BMC Anesthesiol 15: 86

10. Massicotte L, Sassine MP, Lenis S, Roy A (2004) Transfusion predictors in liver transplant. Anesth Analg 98: 1245-1251.

11. Massicotte L, Denault AY, Beaulieu D, Thibeault L, Hevesi Z, et al. (2012) Transfusion rate for 500 consecutive liver transplantations: Experience of one liver transplantation center. Transplantation 93: 1276-1281.

12. Song AT, Avelino-Silva VI, Pecora RA, Pugliese V, D'Albuquerque LA, et al. (2014) Liver transplantation: fifty years of experience. World J Gastroenterol 20: 5363-5374.
13. Dalmau A, Sabaté A, Acosta F, Garcia-Huete L, Koo M, et al. (2000) Tranexamic acid reduces red cell transfusion better than epsilonaminocaproic acid or placebo in liver transplantation. Anesth Analg 91: 29-34.

14. Bolliger D, Görlinger K, Tanaka KA (2010) Pathophysiology and treatment of coagulopathy in massive hemorrhage and hemodilution. Anesthesiology 113: 1205-1219.

15. Ozier Y, Steib A, Ickx B, Nathan N, Derlon A, et al. (2001) Haemostatic disorders during liver transplantation. Eur J Anaesthesiol 18: 208-218.

16. Knot EAR, Porte RJ, Terpstra OT, Schalm SW, Willemse PJ, et al. (1988) Coagulation and fibrinolysis in the first human auxiliary partial liver transplantation in Rotterdam. Fibrinolysis and Proteolysis 2: 111-117.

17. Said A, Lucey MR (2006) Liver transplantation: An update. Curr Opin Gastroenterol 22: 272-278.

18. De Boer MT, Molenaar IQ, Hendriks HG, Slooff MJ, Porte RJ, et al. (2005) Minimizing blood loss in liver transplantation: progress through research and evolution of techniques. Dig Surg 22: 265-275.

19. Lisman T, Porte RJ (2010) Rebalanced hemostasis in patients with liver disease: Evidence and clinical consequences. Blood 116: 878-885.

20. Feltracco P, Barbieri S, Cillo U, Zanus G, Senzolo M, et al. (2015) Perioperative thrombotic complications in liver transplantation. World J Gastroenterol 21: 8004-8013.

21. Boylan JF, Klinck JR, Sandler AN, Arellano R, Greig PD, et al. (1996) Tranexamic acid reduces blood loss, transfusion requirements, and coagulation factor use in primary orthotopic liver transplantation. Anesthesiology 85: 1043-1048.

22. Dalmau A, Sabaté A, Koo M, Bartolomé C, Rafecas A, et al. (2004) The prophylactic use of tranexamic acid and aprotinin in orthotopic liver transplantation: a comparative study. Liver Transpl 10: 279-284.

23. Findlay JY, Rettke SR, Ereth MH, Plevak DJ, Krom RA, et al. (2001) Aprotinin reduces red blood cell transfusion: A prospective, randomized, double-blind study. Liver Transpl 9: 802-807.

24. Segal H, Cottam S, Potter D, Hunt BJ (1997) Coagulation and fibrinolysis in primary biliary cirrhosis compared with other liver disease and during orthotopic liver transplantation. Hepatology 25: 683-688.

25. Xia VW, Steadman RH (2005) Antifibrinolytics in orthotopic liver transplantation: Current status and controversies. Liver Transpl 11: 10-18.

26. Ritter MD, Owen CA Jr, Bowie EJ, Rettke SR, Cole TL, et al. (1989) Evaluation of preoperative haematology-coagulation screening in liver transplantation. Mayo Clin Proc 64: 216-223.

27. Stine JG, Argo CK, Pelletier SJ, Maluf DG, Caldwell SH, et al. (2017) Advanced non-alcoholic steatohepatitis cirrhosis: A high-risk population for pre-liver transplant portal vein thrombosis. World J Hepatol 9: 139-146.

28. Tanaka KA, Bolliger D, Vadlamudi R, Nimmo A (2012) Rotational thromboelastometry (ROTEM)-based coagulation management in cardiac surgery and major trauma. J Cardiothor Vasc Anest 26: 1083-1093.

29. Lang T, Bauters A, Braun SL, Pötzsch B, von Pape KW, et al. (2005) Multicentre investigation on reference ranges for ROTEM thromboelastometry. Blood Coagul Fibrinolysis 16: 301-310.

30. Mallett SV, Chowdary P, Burroughs AK (2013) Clinical utility of viscoelastic tests of coagulation in patients with liver disease. Liver Int 33: 961-974.

31. Krzanicki D, Sugavanam A, Mallett S (2013) Intraoperative hypercoagulability during liver transplantation as demonstrated by thromboelastography. Liver Transpl 19: 852-861.

32. Hiippala ST, Myllyla GJ, Vahtera EM (1995) Hemostatic factors and replacement of major blood loss with plasma-poor red cell concentrates. Anesth Analg 81: 360-365.

33. Harding SA, Mallett SV, Peachey TD, Cox DJ (1997) Use of heparinase modified thrombelastography in liver transplantation. Br J Anaesth 78: 175-179.

34. Kettner SC, Gonano C, Seebach F, Sitzwohl C, Acimovic S, et al. (1998) Endogenous heparin-like substances significantly impair coagulation in 
Citation: Nascimento JCR, Escalante RD, Marinho DS, Fernandes CR, Freire TL, et al. (2017) Thromboelastometric Profile in Patients with Prothrombotic Risk Factors Undergoing Liver Transplantation. J Transplant Technol Res 7: 175. doi:10.4172/2161-0991.1000175

Page 6 of 6

patients undergoing orthotopic liver transplantation. Anesth Analg 86 691-695.

35. Agarwal S, Senzolo M, Melikian C, Burroughs A, Mallett SV, et al. (2008) The prevalence of a heparin-like effect shown on the thromboelastograph in patients undergoing liver transplantation. Liver Transpl 14: 855-860.

36. Marcel RJ, Stegall WC, Suit CT, Arnold JC, Vera RL, et al. (1996) Continuous small-dose aprotinin controls fibrinolysis during orthotopic liver transplantation. Anesth Analg 82: 1122-1125.

37. Poon KS, Chen CC, Thorat A, Chiang YY, Jeng LB, et al. (2015) Fibrinolysis after reperfusion of liver graft. Acta Anaesthesiol Taiwan 53: 41-43.

38. Himmelreich G, Dooijewaard G, Breinl P, Bechstein WO, Neuhaus P, et al. (1993) Evolution of urokinase-type plasminogen activator (u-PA) and tissue-type plasminogen activator (t-PA) in orthotopic liver transplantation (OLT). Thromb Haemost 69: 56-59.

39. Dzik WH, Arkin CF, Jenkins RL, Stump DC (1998) Fibrinolysis during liver transplantation in humans: role of tissue-type plasminogen activator Blood 71: 1090-1095.

40. Senzolo M, Burra P, Cholongitas E, Burroughs AK (2006) New insights into the coagulopathy of liver disease and liver transplantation. World J Gastroenterol 12: 7725-7736.
41. Bakker CM, Blankensteijn JD, Schlejen P, Porte RJ, Gomes MJ, et al. (1994) The effects of long-term graft preservation on intraoperative hemostatic changes in liver transplantation. A comparison between orthotopic and heterotopic transplantation in the pig. HPB Surg 7: 265-280.

42. Kang Y, Lewis JH, Navalgund A, Russell MW, Bontempo FA, et al. (1987) Epsilon-aminocaproic acid for treatment of fibrinolysis during liver transplantation. Anesthesiology 66: 766-773.

43. Hu KQ, Yu AS, Tiyyagura L, Redeker AG, Reynolds TB (2001) Hyperfibrinolytic activity in hospitalized cirrhotic patients in a referral liver unit. Am J Gastroenterol 96: 1581-1586.

44. Roullet S, Pillot J, Freyburger G, Biais M, Quinart A, et al. (2010) Rotation thromboelastometry detects thrombocytopenia and hypofibrinogenaemia during orthotopic liver transplantation. $\mathrm{Br} \mathrm{J}$ Anaesth 104: 422-428.

45. Theusinger OM, Stein P, Levy JH (2015) Point of care and factor concentrate-based coagulation algorithms. Transfus Med Hemother 42: $115-121$. 